\title{
Effect of Mercerization on the Properties of Pandanus Odorifer Lignocellulosic Fibre
}

\author{
Mangesh Teli ${ }^{1}$, Akshay Jadhav $^{2}$ \\ ${ }^{1}$ Professor, Dept. of Fibres and Textile Processing Technology, Institute of chemical Technology, Mumbai- \\ 400019, Maharashtra, India \\ ${ }^{2}$ Ph.D scholar, Dept. of Fibres and Textile Processing Technology, Institute of chemical Technology, Mumbai- \\ 400019, Maharashtra, India
}

\begin{abstract}
Pandanus Odorifer (PO) fibre species were treated with varied concentrations $(2-20 \%) \mathrm{NaOH}$ at room temperature for $1 \mathrm{~h}$ and physical properties were evaluated. Chemical composition of the treated fibres showed that hemicellulose was removed to a varied extent by mercerization. Tensile strength of the treated fibres, their moisture content, surface morphology (by Scanning electron microscope), crystallinity index by XRD analysis and thermal degradation (TGA) were analysed. The alkali treated fibres between 2 to $15 \%$ showed all round improvement in the properties as compared to with those of untreated raw fibres.
\end{abstract}

Keywords: Extraction, Hemicellulose, mercerization, Pandanus Odorifer, Retting.

\section{Introduction}

Natural plant fibres are easily obtained in many tropical parts and are available throughout the world. Natural fibres present important advantages such as low density, appropriate stiffness, good mechanical properties and high disposability and renewability. There has been a lot of research carried out on the use of natural fibres in reinforcements and textile industry $[1,2]$. Recently, due to the improved standard of living of the people and need for environmental protection, the demand of natural biodegradable and eco-friendly fibres is increased worldwide. Natural fibres have attracted worldwide attention as a potential reinforcement of composites because of their easy availability, as renewable resource, easy processability, low density, lightweight, non-abrasivity, nonhazardousness, recycling nature, low cost and above all environmental friendly characteristics. The natural fibres are lignocellulosic materials consisting of alpha cellulose as the main component along with hemicellulose and lignin as other components [3-5]. Many types of natural fibres have been investigated and used in reinforced composites including flax, hemp, jute, straw, wood fibre, rice husks, wheat, barley, oats, rye, cane (sugar and bamboo), grass reeds, kenaf, ramie, oil palm empty fruit bunch, sisal, coir, water hyacinth, pennywort, kapok, paper-mulberry, raffia, banana fibre, pineapple leaf fibre, papyrus and many more [6]. On the other hand, these lignocellulosic agricultural wastes can be transformed into valuable products (materials, chemicals, energy) for various applications via chemical, thermo-chemical, biochemical, and physical conversion [7]. Agro based lignocellulosic by products such as rice husks, wheat straw have also been used as raw material for production of bioethanol, chemicals, enzymes, proteins, pharmaceuticals and fibre reinforced polymer composites [8]. Thus, the usage of cheap plant fibres, vegetable fibres and agro-waste by products is becoming increasingly attractive in preparation of green composites as reinforcement material.

Plant fibres are highly polar due to the presence of the hydroxyl groups, which are readily available for the formation of hydrogen bonds with interacting, resin matrices. Various chemical treatments of natural fibre are carried out before manufacturing composite material so that water sorption can be reduced by substituting the hydroxyl group by less polar groups. Various fibre surface treatments like mercerization, isocyanate treatment, acrylation, permanganate treatment, acetylation, silane treatment and peroxide treatment have been carried out which may result in improving properties of composite $[9,10,11]$. Most preferred surface modification of natural fibres is $\mathrm{NaOH}$ treatment. A significant improvement in mechanical property of natural fibres can be attained by alkali treatment [12].The process of alkali treatment is also called as mercerization. The reaction between fibre and $\mathrm{NaOH}$ is shown below.

$$
\text { Fibre-OH }+\mathrm{NaOH} \longrightarrow \text { Fibre }-\mathrm{O}-\mathrm{Na}^{+}+\mathrm{H}_{2} \mathrm{O}+\text { Surface impurities }
$$

Mercerization reduces the amorphous materials like waxes, pectins and hemicellulose, which results in increase of their surface roughness, thermal stability and compatibility to non-polar polymer matrix which in turn improves its mechanical properties [13, 14].

In the present work, fibres were extracted from the leaves of the Pandanus Odorifer (PO) plant. It is an aromatic monocot species of plant in the Pandanaceae family, native to Polynesia, Australia, South Asia (Andaman Islands), and the Philippines and is also found in the wild in southern India and Burma. It is commonly known as screw-pine. It is a small branched, palm-like dioecious tree with a flexuous trunk 
supported by brace roots. The tree can grow to a height of 4 meters. Leaves grow in clusters at the branch tips, with rosettes of sword-shaped, stiff and spiny bluish-green, fragrant leaves. Leaves are glaucous, 40-70 cm. long. In summer, the tree bears very fragrant flowers [15]. Aromatic oil (kevda oil) and fragrant distillate (otto) called keorra-ka-arak are extracted from the male flowers. They are almost exclusively used in the form of a watery distillate called kewra water. It is also called as Kevda plant in India. So an attempt has been made here to investigate the properties of PO fibres and to explore its further potential to be used as textile as well as composite material.

\subsection{Materials}

\section{Methods And Materials}

The fibres were extracted from the leaves of the PO plant which was harvested from the rural areas of Maharashtra, India. The fibres were used without any pre-treatment or purification. The chemical reagents of analytical grade, such as sulphuric acid, sodium chlorite, sodium bisulphate, glacial acetic acid, sodium hydroxide, ethanol, toluene were procured from SD Fine Chemicals Ltd., India.

\subsection{Methods \\ 2.2.1 Fibre extraction}

The fibres were extracted from the matured leaves of the PO plant. These matured leaves consisted of thorns on the edges and a sharp and pointed thorn at the tip of the leaf. These thorns were removed with the help of a knife. After this the leaves were directly subjected for water retting for 15 days. These leaves after retting were removed from the water and dried in sun and later were stripped off by using metal comb to get the fibres. These fibres were washed continuously under running tap water to get clean fibres and were made suitable for physical, chemical and morphological analysis.

\subsubsection{Mercerization of fibres}

The PO fibres were chopped to a length of $10 \mathrm{~cm}$ and treated with different concentrations $(2 \%, 5 \%$, $10 \%, 15 \%, 20 \% \mathrm{w} / \mathrm{v}$ ) of aqueous solutions of $\mathrm{NaOH}$ at room temperature for $1 \mathrm{hr}$ using material to liquor ratio 1:30. The fibres were then removed and washed continuously with water, neutralized with dilute acetic acid and washed again with fresh water. The fibres were there after dried at $65{ }^{\circ} \mathrm{C}$ in hot air oven for $24 \mathrm{~h} \mathrm{[16].}$

\subsubsection{Determination of chemical composition}

The chemical composition of the PO raw fibres and mercerized fibre was determined by chopping the fibres into small pieces. These chopped fibres were weighed and dewaxing was carried out by boiling the fibres in a mixture of toluene/ethanol $(2: 1 \mathrm{v} / \mathrm{v})$ in a soxhlet apparatus for $6 \mathrm{~h}$. The de-waxed fibres were then filtered, washed with ethanol, and dried. The acid-insoluble lignin content was determined according to TAPPI T222 om-02. In this method of determination, lignin (also known as "Klasons lignin") is defined as constituents of fibres insoluble in 72\% sulphuric acid. The $\alpha$-cellulose content was determined by TAPPI T $203 \mathrm{~cm}-99$ and ash content was determined by standard method of Tappi T $211 \mathrm{om}-02$.

\subsubsection{Morphological studies}

The scanning electron micrographs of the fibre surface were recorded on a microscope (JEOL JSM 6380LA, Japan) from Institute of Chemical Technology. The fibre samples were sputter coated with platinum before recording the micrographs.

\subsubsection{FTIR analysis}

The IR spectra of raw and mercerized PO fibre samples were recorded using FTIR spectrophotometer (Shimadzu 8400s, Japan) using ATR sampling technique by recording 45 scans in \% transmittance mode in the range of $4000-600 \mathrm{~cm}^{-1}$.

\subsubsection{XRD analysis}

The crystallinity of raw and mercerized PO fibres was studied using an X-ray diffractometer (Shimadzu 6100, Japan) equipped with $\mathrm{CuK} \alpha$ radiation $\left(\lambda=1.54{ }^{\circ} \mathrm{A}\right)$ in the $2 \theta$ range $5-30^{\circ}$. The experiments were performed in the reflection mode at a scan speed of $2^{\circ} / \mathrm{min}$ in steps of $0.02^{\circ}$. The crystallinity index $(\mathrm{CrI})$ of the fibre was calculated according to the empirical method shown in the following equation [17].

$\mathrm{CrI} \%=\mathrm{I}_{002}-\mathrm{I}_{\mathrm{am}} / \mathrm{I}_{002} \times 100$

where $\mathrm{I}_{002}$ and $\mathrm{I}_{\mathrm{am}}$ are the peak intensities of crystalline and amorphous materials, respectively. 


\subsubsection{Thermal analysis}

The samples of untreated and mercerized PO fibres were cut into small pieces and thermo gravimetric analysis (TGA) was carried out. The thermograms were recorded on Shimadzu 60H DTG machine using aluminium pan between temperature range $30-500{ }^{\circ} \mathrm{C}$ under the inert atmosphere of nitrogen at a flow rate of $50 \mathrm{ml} / \mathrm{min}$.

\subsubsection{Tensile properties and Moisture regain}

The tensile properties of the fibres were measured according to ISO 5079; 1996 method in terms of the breaking load, percentage elongation at breaking using Tinius Olsen tensile testing machine. A gauge length of $20 \mathrm{~mm}$ with a speed of $5 \mathrm{~mm} / \mathrm{min}$ were used for the testing. Approximately 15 fibres were tested for their tensile properties and an average was recorded. To identify the moisture content values, the fibre sample was tested according to ASTM standard method 2495.

\section{Results And Discussions}

\subsection{Determination of chemical composition}

The results of chemical composition studies of untreated and mercerized PO fibres shown in Table. 1, reveals that the mercerization caused distinct change in chemical composition of the fibre with respect to $\alpha$ cellulose, hemicellulose and lignin content. Before the chemical composition was determined, the untreated and alkali treated fibres were dewaxed by extracting the chopped fibres in toluene/ethanol solvents $(2: 1 \mathrm{v} / \mathrm{v})$ [18]. The percentage of extractable matter decreased as the alkali concentration increased from $2 \%$ to $20 \%$. This might be because the mercerization removed most of the wax and surface impurities from the fibres. The hemicelluloses content also distinctly decreased with increase in the concentrations of the sodium hydroxide solution which may be attributed to its relatively much more sensitive nature to the action of aqueous sodium hydroxide at room temperature than lignin or $\alpha$-cellulose [11]. The hemicellulose content of the PO fibres was found to be reduced from $30 \%$ in raw fibre to $12 \%$ for PO fibres treated with $20 \% \mathrm{NaOH}$ solution. It is well known that hemicelluloses dissolves in alkali and hence, mercerized PO fibre showed consequent increase in relative percentage of $\alpha$-cellulose and lignin. Ash content also decreased from $2.5 \%$ to $0.5 \%$ as most of the impurities such as wax, pectins, fatty substances etc. were removed during the mercerization.

Table 1. Chemical composition of raw and mercerized PO fibres

\begin{tabular}{|c|c|c|c|c|c|}
\hline Fibres & $\begin{array}{c}\text { Extractives in } \\
\text { solvent }(\%)\end{array}$ & $\begin{array}{c}\text { Lignin } \\
\%\end{array}$ & $\begin{array}{c}\text { Hemicellulose } \\
\%\end{array}$ & $\begin{array}{c}\text { Cellulose } \\
\%\end{array}$ & $\begin{array}{c}\text { Ash content } \\
\%\end{array}$ \\
\hline Raw & 2.5 & 21 & 30 & 44 & 2.5 \\
\hline $2 \% \mathrm{NaOH}$ & 2 & 23 & 27 & 46 & 2 \\
\hline $5 \% \mathrm{NaOH}$ & 2 & 24 & 25 & 47 & 2 \\
\hline $10 \% \mathrm{NaOH}$ & 1.5 & 25 & 23 & 49 & 1.5 \\
\hline $15 \% \mathrm{NaOH}$ & 1 & 26 & 17 & 55 & 1 \\
\hline $20 \% \mathrm{NaOH}$ & 0.5 & 27 & 12 & 60 & 0.5 \\
\hline
\end{tabular}

\subsection{SEM analysis}

Figure. 1, shows the SEM photographs of untreated and mercerized PO fibres with different concentrations of $\mathrm{NaOH}$. On mercerization the fibres became more thinner and the pores became more clearer. The mercerized fibres showed a large number of voids or pit holes on the surface of the fibre with increasing concentration of alkali. This might be because of the removal of fatty substances called tyloses from the surface of the fibre creating holes [19]. The diameter of the fibre also decreased with increasing alkali concentration (Refer Table 2). This is due to the removal of hemicellulose and other surface impurities which resulted in surface roughness. Thus mercerization resulted in significant changes in fibre morphology. 


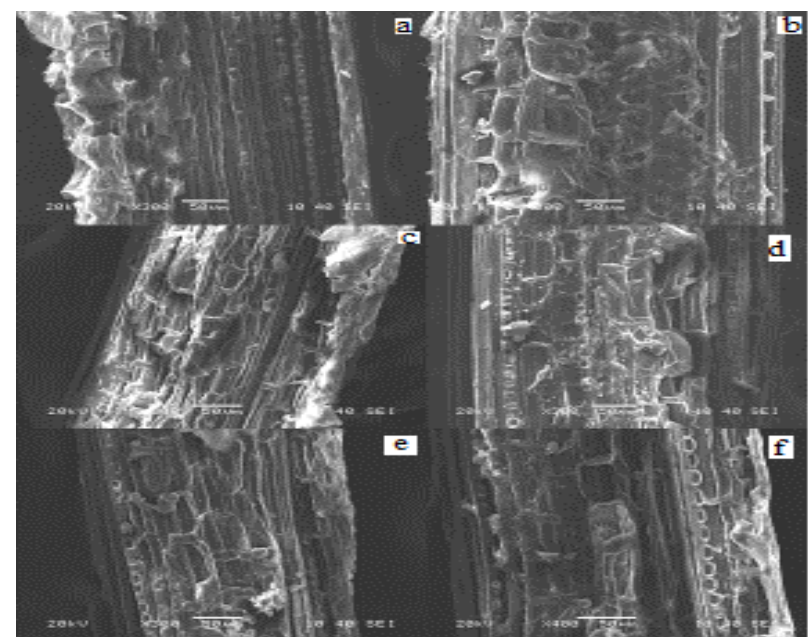

Fig 1. a) Raw fibre, b) $2 \% \mathrm{NaOH}$ treated fibre, c) $5 \% \mathrm{NaOH}$ treated fibre, d) $10 \% \mathrm{NaOH}$ treated fibre, e) $15 \%$ $\mathrm{NaOH}$ treated fibre f) $20 \% \mathrm{NaOH}$ treated fibre

Table 2. Physical properties of the fibres

\begin{tabular}{|c|c|c|c|}
\hline NaOH concentrations & $\begin{array}{c}\text { Average length } \\
\mathrm{L}(\mathrm{cm})\end{array}$ & $\begin{array}{c}\text { Average diameter } \\
\mathrm{D}(\mathrm{cm})\end{array}$ & $\begin{array}{c}\text { Aspect ratio } \\
\text { L/D }\end{array}$ \\
\hline Untreated & 10 & 0.03775 & 264.90 \\
\hline $2 \%$ & 10 & 0.03733 & 267.88 \\
\hline $5 \%$ & 10 & 0.03652 & 273.82 \\
\hline $10 \%$ & 10 & 0.03442 & 290.52 \\
\hline $15 \%$ & 10 & 0.03397 & 294.37 \\
\hline $20 \%$ & 10 & 0.02741 & 364.83 \\
\hline
\end{tabular}

\subsection{FTIR analysis}

The IR spectra of untreated and mercerized PO fibre is given in Figure. 2. The strong broad peak at $3300-3320 \mathrm{~cm}^{-1}$ is the characteristic hydrogen-bonded $-\mathrm{OH}$ stretching vibration. The IR spectrum of raw fibre shows an absorption peak at $1735 \mathrm{~cm}^{-1}$, which is the characteristic band for carbonyl stretching, associated with the carbonyl groups present in lignin and other cellulosic components. The peak at $1255 \mathrm{~cm}^{-1}$ showed $\mathrm{CH}$ bending of hemicellulose [20, 21]. A band at $1591 \mathrm{~cm}^{-1}$ is due to the C-C stretching of the aromatic ring in the lignin components. The important change expected as a result of mercerization, the removal of the hydrogen bonding in the network which is evident from the increased intensity of the $-\mathrm{OH}$ peaks at $3300 \mathrm{~cm}^{-1}$. Also, on mercerization, the peak at $1735 \mathrm{~cm}^{-1}$ and $1255 \mathrm{~cm}^{-1}$ in the spectrum of the raw fibre disappeared. This is due to the fact that a substantial amount of uranic acid, a constituent of hemi-cellulose (xylan) is removed from the fibre, resulting in the disappearance of the peak. Similarly the peak observed at $1378 \mathrm{~cm}^{-1}$ indicates the presence of lignin and it shows diminishing intensity as the fibres are subjected to higher concentration of alkali [10]. Rest of the vibrations are summarized in Table. 3.

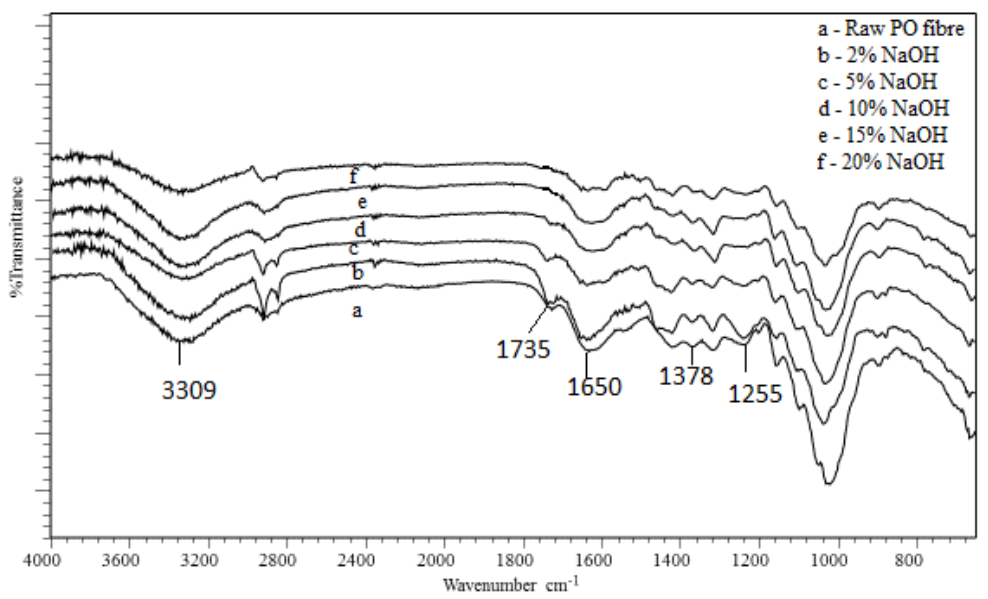

Fig. 2. FTIR spectrum of raw and $\mathrm{NaOH}$ treated $\mathrm{PO}$ fibre 
Table 3. Possible assignment of frequencies $\left(\mathrm{cm}^{-1}\right)$ of functional groups in untreated and mercerized PO fibres.

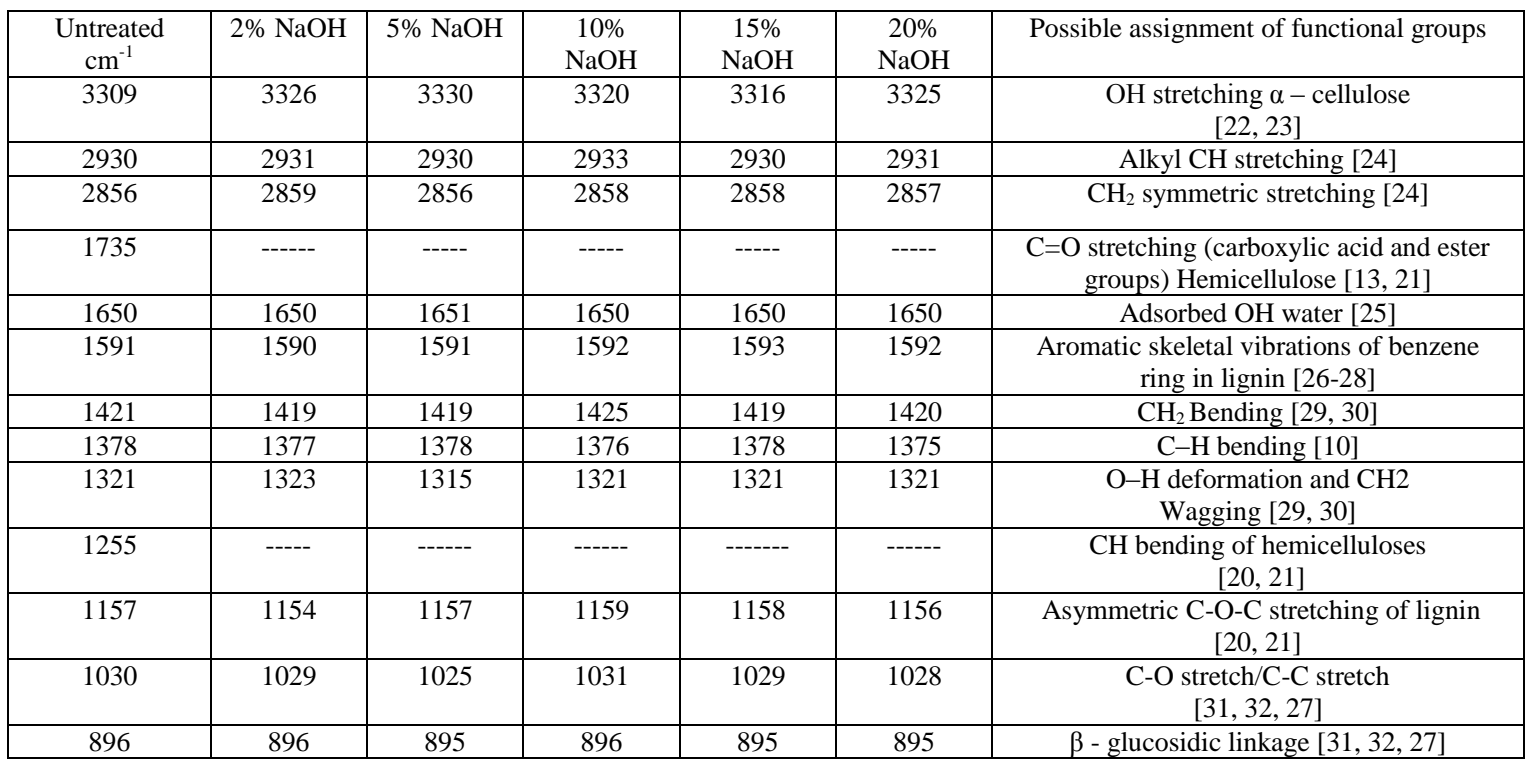

\subsection{XRD analysis}

The X-ray diffraction patterns of untreated and mercerized PO fibres are shown in the Fig. 3.The diffractogram showed two reflections, corresponding to $2 \theta$ values of around $16^{\circ}$ and $22^{\circ}$, respectively. Among these, the low angle reflection $\left(16^{\circ}\right)$ was of low intensity, representing $\mathrm{I}_{(\mathrm{am})}$ of amorphous material and the other reflection $\left(22^{\circ}\right)$ had higher intensity, and it represented $\mathrm{I}_{(002)}$ of crystalline material in cellulosic fibre. It was seen that the degree of crystallinity of mercerized PO fibres increased as the concentration of alkali increased upto 15\% (Refer Table. 4). This might be because of the removal of hemicellulose which results in close packing of cellulosic chain. However at $20 \%$ alkali concentration, it was observed that the crystallinity of the fibre decreased indicating there by degradation of cellulose structure [18]. The degree of crystallinity (CrI\%) was calculated using Eq (1) described in experimental part of this paper.

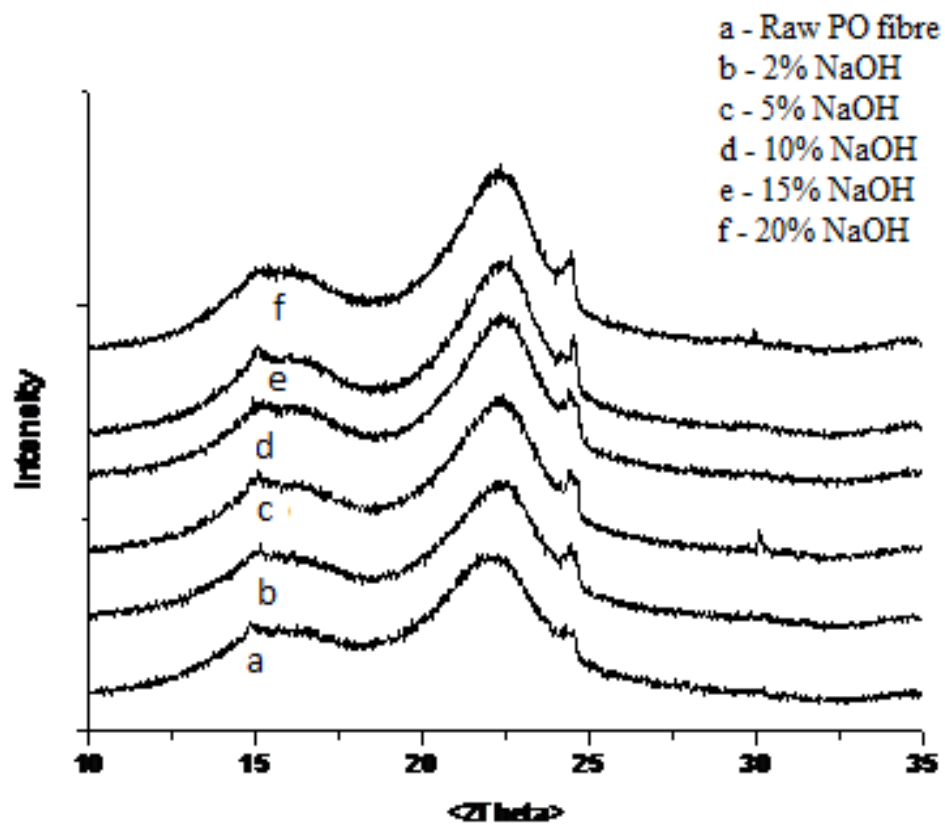

Fig.3. XRD analysis of raw and mercerized fibres 
Table 4. Crystallinity Index of raw and $\mathrm{NaOH}$ treated $\mathrm{PO}$ fibres

\begin{tabular}{|c|c|c|c|}
\hline Sample & $\mathrm{I}(\mathrm{am})$ at $2 \Theta 15.5$ & $\mathrm{I}(002)$ at $2 \Theta 22$ & $\mathrm{CrI} \%$ \\
\hline $\mathrm{Raw} \mathrm{PO}$ & 318 & 588 & 46.01 \\
\hline $2 \% \mathrm{NaOH}$ & 588 & 1439 & 59.10 \\
\hline $5 \% \mathrm{NaOH}$ & 667 & 1631 & 59.80 \\
\hline $10 \% \mathrm{NaOH}$ & 658 & 1725 & 61.85 \\
\hline $15 \% \mathrm{NaOH}$ & 710 & 1881 & 62.25 \\
\hline $20 \% \mathrm{NaOH}$ & 762 & 1829 & 58.33 \\
\hline
\end{tabular}

\subsection{TGA analysis}

The thermograms of untreated and mercerized PO fibres are shown in Fig. 4. All lignocellulosic fibres are mainly composed of cellulose, hemicellulose and lignin. The first degradation temperature ranges from 50 $125{ }^{\circ} \mathrm{C}$ corresponding to the evaporation of moisture. The second degradation step of untreated fibres was observed at temperature range of $200-300{ }^{\circ} \mathrm{C}$ which indicated the loss of hemicellulose and some part of the lignin. The third decomposition step corresponded to the decomposition of cellulose in the range of $300-400$ ${ }^{\circ} \mathrm{C}$. Similar observation was also made in the case of many natural fibres. The first peak below $100^{\circ} \mathrm{C}$ was the result of evaporation of moisture. Wax, pectin, and hemicelluloses in it will degrade around $180{ }^{\circ} \mathrm{C}$, cellulose at around $300{ }^{\circ} \mathrm{C}$, and lignin at around $400{ }^{\circ} \mathrm{C}$, respectively. The decomposition temperatures, percentage degradations and char content of untreated and alkali treated fibres showed remarkable differences. These values are presented in Table 5. It was observed that the residual char left at $500{ }^{\circ} \mathrm{C}$ increased considerably from $21.50 \%$ to $32.89 \%$ in the case of all the treated fibres. From this table, it is clearly evident that the thermal stability parameters of the mercerized fibres were higher than those of the untreated fibres. This might be due to the removal of amorphous hemicelluloses from the fibres by alkali-treatment. Mercerization reduced the hemicellulose to a considerable extent, giving rise to lignin-cellulose complex, thereby making the product more stable than the untreated sample, and this reflected in the increased amount of residual char [33, 34]. The thermal stability of the fibres treated with $20 \%$ alkali concentration decreased as compared to that of $15 \%$ alkali treated fibres. The char content also decreased to $30.59 \%$. This is in support of the earlier observation in other properties of the fibres treated with $20 \%$ alkali solution indicating the degradation of cellulose at this concentration. The removal of the amorphous hemi cellulose of the fibres on alkali treatment might have led to the increase in the \% crystallinity of the fibres facilitating improved thermal and mechanical properties [16].

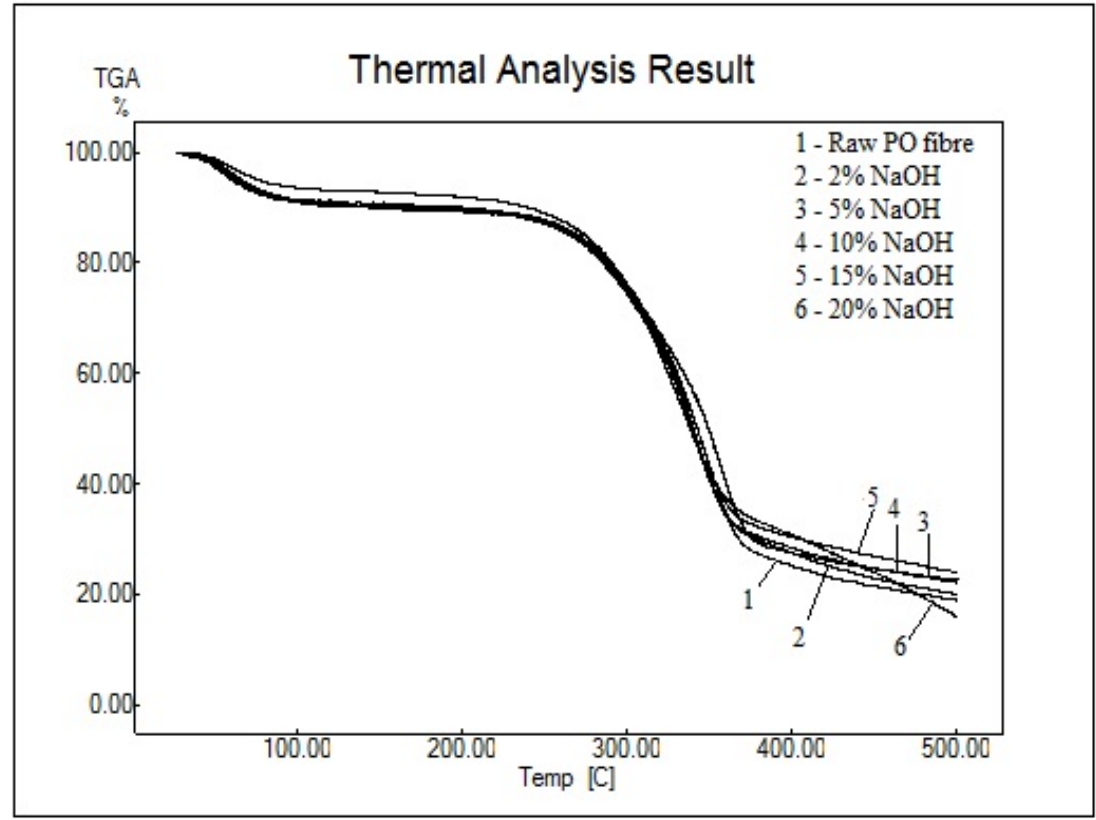

Fig. 4. TGA analysis of raw and $\mathrm{NaOH}$ treated fibre 
Table 5. Results of TGA analysis of raw and mercerized PO fibres

\begin{tabular}{|c|c|c|c|}
\hline Fibres & $\begin{array}{l}\text { Peak temperature } \\
{ }^{\circ} \mathrm{C}\end{array}$ & $\begin{array}{c}\text { Degradation } \\
\%\end{array}$ & $\begin{array}{l}\text { Residue at } 500{ }^{\circ} \mathrm{C} \\
\text { Char content, } \%\end{array}$ \\
\hline \multirow[t]{3}{*}{ Raw PO } & 83.12 & 9.72 & \multirow{3}{*}{21.50} \\
\hline & 298.01 & 15.53 & \\
\hline & 369.21 & 53.25 & \\
\hline \multirow[t]{3}{*}{$2 \% \mathrm{NaOH}$} & 80.21 & 9.46 & \multirow{3}{*}{25.68} \\
\hline & 296.23 & 15.11 & \\
\hline & 364.35 & 49.75 & \\
\hline \multirow{3}{*}{$5 \% \mathrm{NaOH}$} & 76.47 & 9.38 & \multirow{3}{*}{28.90} \\
\hline & 296.24 & 14.84 & \\
\hline & 359.35 & 46.88 & \\
\hline \multirow[t]{3}{*}{$10 \% \mathrm{NaOH}$} & 74.54 & 8.56 & \multirow{3}{*}{30.23} \\
\hline & 298.14 & 13.86 & \\
\hline & 356.16 & 47.35 & \\
\hline \multirow[t]{3}{*}{$15 \% \mathrm{NaOH}$} & 73.24 & 8.01 & \multirow{3}{*}{32.89} \\
\hline & 297.12 & 13.48 & \\
\hline & 360.27 & 45.62 & \\
\hline \multirow[t]{3}{*}{$20 \% \mathrm{NaOH}$} & 68.05 & 7.10 & \multirow{3}{*}{30.59} \\
\hline & 298.31 & 14.60 & \\
\hline & 358.20 & 47.71 & \\
\hline
\end{tabular}

\subsection{Tensile and moisture regain properties}

It was observed that the tensile strength and elongation (\%) of the mercerized fibres were enhanced in comparision to untreated PO fibre. The tensile properties and moisture content values are hereby summarized in Table 6. The tensile properties of the PO fibres increased till particular alkali concentration i.e. from 2 to $15 \%$; further increase in alkali concentration resulted in decrease in tensile properties. This might be because of the removal of amorphous hemicellulose in the initial phase and other waxy substance from the fibre on alkali treatment which increases the overall crystallinity of the fibre. The cellulose chains in the fibre are always in a constant state of strain due to the dispersion of hemicelluloses and lignin into the inter-fibrillar region of fibre structure separating the cellulose chains from each other. But after alkali treatment, the hemicellulose is removed to a large extent from the fibre. Due to this the fibrils rearrange themselves in a compact manner which leads to a close packing of the cellulose chains, which ultimately results in the improvement of tensile properties of the alkali treated SR fibres [35]. Similarly the moisture content of the mercerized fibres also decreased with increase in alkali concentration as compared to that of the untreated fibres. Thus mercerized fibres lead to reduction of free hydroxyl groups which ultimately increased the crystallinity and there by reduced the amorphous content of the fibre. This is in support to XRD and TGA results discussed earlier.

Table 6. Tensile properties and moisture content of raw and mercerized fibres.

\begin{tabular}{|c|c|c|c|}
\hline Fibres & $\begin{array}{c}\text { Tensile strength } \\
\text { gf }\end{array}$ & $\begin{array}{c}\text { Elongation } \\
\%\end{array}$ & $\begin{array}{c}\text { Moisture content } \\
\%\end{array}$ \\
\hline Raw & 572.1 & 4.81 & 9.72 \\
\hline $2 \% \mathrm{NaOH}$ & 595.3 & 4.95 & 9.46 \\
\hline $5 \% \mathrm{NaOH}$ & 612.5 & 5.50 & 9.38 \\
\hline $10 \% \mathrm{NaOH}$ & 635.6 & 5.71 & 8.56 \\
\hline $15 \% \mathrm{NaOH}$ & 684.2 & 5.90 & 8.01 \\
\hline
\end{tabular}

\section{Conclusion}

Pandanus odorifer (PO) fibre on treatment with increasing concentration of $\mathrm{NaOH}$ upto $15 \%$, showed increase in crystallinity as a result of dissolution and removal of amorphous hemicellulose. Such an increase in crystallinity is also confirmed by X-ray diffraction. TGA also supported the same showing increase in thermal stability. The tensile strength of the fibres treated with alkali increased and maximum increase was observed in case of $15 \%$ alkali concentration. However, beyond this concentration at $20 \%$ alkali concentration, due to decrystallisation strength was decreased and also thermal stability. Hence $15 \%$ alkali treatment of PO fibres can give maximum increase in crystallinity and tensile properties and hence could offer maximum reinforcement to the composite material. 


\section{Acknowledgement}

The authors gratefully acknowledge the Fellowship from University Grants Commission (UGC-SAP), India, for carrying out this research work.

\section{References}

[1]. Chowdhury, M. N. K., Beg, M. D. H., Khan, M. R., \& Mina, M. F. Modification of oil palm empty fruit bunch fibres by nanoparticle impregnation and alkali treatment. Cellulose, 20(3), 2013, 1477-1490.

[2]. Nourbakhsh, A., Ashori, A., \& Kouhpayehzadeh, M. Giant Milkweed (Calotropis persica) Fibres -A Potential Reinforcement Agent for Thermoplastics Composites. Journal of Reinforced Plastics and Composites, 28(17), 2009, 2143-2149.

[3]. Rajulu, A.V., Nadhan, A.V., \& Devi, R.R. Properties of lingo-cellulosic bilayered vegetable fabric from ridge gourd. Journal of applied polymer science, 102(3), 2006, 2338-2342.

[4]. John, M. J., \& Anandjiwala, R. D. Recent developments in chemical modification and characterization of natural fibre-reinforced composites. Polymer Composites, 29(2), 2008, 187-207.

[5]. Maheswari, C. U., Guduri, B. R., \& Rajulu, A. V. Properties of lignocellulose tamarind fruit fibres. Journal of Applied Polymer Science, 110(4), 2008, 1986-1989.

[6]. Teli, M. D., \& Jadhav, A. C. Extraction and Characterization of Novel Lignocellulosic Fibre. Journal of Bionanoscience, 10(5), 2016, 418-423(6).

[7]. Clark, J., and Deswarte, F., (2008). The biorefinery concept: An integrated approach. In Introduction to chemicals from biomass,. John Wiley \& Sons.

[8]. Paster, M., Pellegrino, J.L., and Carole, T.M. Industrial bioproducts; today and tomorrow. 2003.

[9]. Bledzki, A., \& Gassan, J. Composites reinforced with cellulose based fibres. Progress in Polymer Science, 24(2), 1999, 221-274.

[10]. Mwaikambo, L. Y., \& Ansell, M. P. Chemical modification of hemp, sisal, jute, and kapok fibres by alkalization. Journal of Applied Polymer Science, 84(12), 2002, 2222-2234.

[11]. Bledzki, A. K., Reihmane, S., \& Gassan, J. Properties and modification methods for vegetable fibres for natural fibre composites. Journal of Applied Polymer Science, 59(8), 1996, 1329-336.

[12]. Van de Weyenberg, I., Chi Truong, T., Vangrimde, B., \& Verpoest, I. Improving the properties of UD flax fibre reinforced composites by applying an alkaline fibre treatment. Composites Part A: Applied Science and Manufacturing, 37(9), 2006, 13681376.

[13]. Teli, M. D and Jadhav, A.C. Effect of alkali treatment on the properties of Agave augustifolia v. marginata fibre. International Research Journal of Engineering and Technology (IRJET). 3(5), 2016, 2754-2761

[14]. Arrakhiz, F. Z., El Achaby, M., Kakou, A. C., Vaudreuil, S., Benmoussa, K., Bouhfid, R., Qaiss, A. Mechanical properties of high density polyethylene reinforced with chemically modified coir fibres: Impact of chemical treatments. Materials \& Design, 37, 2012, 379-383.

[15]. Nadaf, A., \& Zanan, R. Indian Pandanaceae - an overview. New Delhi: Springer India, 2012.

[16]. Teli, M. D., \& Jadhav, A. C. Effect of alkalization on the properties of Abelmoschus Manihot lignocellulosic fibre. International Journal of Current Engineering and Technology, 5(6), 2015, 2277-4106.

[17]. Segal, L.G.J.M.A., Creely, J.J., Martin, A.E. and Conrad, C.M. An empirical method for estimating the degree of crystallinity of native cellulose using the X-ray diffractometer. Textile Research Journal, 29(10), 1959, 786-794.

[18]. Das, M., \& Chakraborty, D. Evaluation of improvement of physical and mechanical properties of bamboo fibres due to alkali treatment. Journal of Applied Polymer Science, 107(1), 2008, 522-527.

[19]. Prasad, S. V., Pavithran, C., \& Rohatgi, P. K. Alkali treatment of coir fibres for coir-polyester composites. Journal of Materials Science, 18(5), 1983, 1443-1454

[20]. Pandey, K. K. A study of chemical structure of soft and hardwood and wood polymers by FTIR spectroscopy. Journal of Applied Polymer Science, 71(12), 1999, 1969-1975.

[21]. Liu, D., Han, G., Huang, J., \& Zhang, Y. Composition and structure study of natural Nelumbo nucifera fibre. Carbohydrate Polymers, 75(1), 2009, 39-43.

[22]. Saha, S. C., Das, B. K., Ray, P. K., Pandey, S. N., \& Goswami, K. Infrared spectra of raw and chemically modified pineapple leaf fibre (annanus comosus). Journal of Applied Polymer Science, 43(10), 1991, 1885-1890

[23]. Pandey, K., \& Pitman, A. FTIR studies of the changes in wood chemistry following decay by brown-rot and white-rot fungi. International Biodeterioration \& Biodegradation, 52(3), 2003, 151-160.

[24]. Sun, X. F., Xu, F., Sun, R. C., Fowler, P., \& Baird, M. S. Characteristics of degraded cellulose obtained from steam-exploded wheat straw. Carbohydrate Research, 340(1), 2005, 97-106.

[25]. Lojewska, J., Misowiec, P., Qojewski, T., \& Proniewicz, L. M. Cellulose oxidative and hydrolytic degradation: In situ FTIR approach. Polymer degradation and stability, 88(3),2005, 512-520

[26]. Paiva, M. C., Ammar, I., Campos, A. R., Cheikh, R. B., \& Cunha, A. M. Alfa fibres: Mechanical, morphological and interfacial characterization. 2006

[27]. Silva, M. C., Lopes, O. R., Colodette, J. L., Porto, A. O., Rieumont, J., Chaussy, D., Silva, G. G. Characterization of three nonproduct materials from a bleached eucalyptus kraft pulp mill, in view of valorising them as a source of cellulose fibres. Industrial crops and Products,27(3), (2008), 288-295.

[28]. Joseph, K., Thomas, S., \& Pavithran, C. Effect of chemical treatment on the tensile properties of short sisal fibre-reinforced polyethylene composites. Polymer, 37(23), 1996, 5139-5149.

[29]. Alemdar, A., \& Sain, M. Isolation and characterization of nanofibres from agricultural residues - Wheat straw and soy hulls. Bioresource Technology, 99(6), 2008, 1664-1671.

[30]. Nazir, M. S., Wahjoedi, B. A., Yussof, A. W., \& Abdullah, M. A. Eco-Friendly Extraction and Characterization of Cellulose from Oil Palm Empty Fruit Bunches. BioResources, 8(2), 2013, 2161-2172.

[31]. Popescu, C.M., Larsson, P. T., Olaru, N., \& Vasile, C. Spectroscopic study of acetylated kraft pulp fibres. Carbohydrate Polymers, 88(2), 2012, 530-536.

[32]. Oh, S. Y., Yoo, D. Il, Shin, Y., Kim, H. C., Kim, H. Y., Chung, Y. S., Youk, J. H. Crystalline structure analysis of cellulose treated with sodium hydroxide and carbon dioxide by means of X-ray diffraction and FTIR spectroscopy. Carbohydrate Research, 340(15), $2005,2376-2391$. 
[33]. Reddy, K. O., Maheswari, C. U., Reddy, D. J. P., \& Rajulu, A. V. Thermal properties of Napier grass fibres. Materials Letters (Vol. 63). 2009

[34]. Ray, D., Sarkar, B. K., Basak, R. K., \& Rana, A. K. Study of the thermal behavior of alkali-treated jute fibres. Journal of Applied Polymer Science, 85(12), 2002, 2594-2599.

[35]. Sinha, E., \& Rout, S. K. Influence of fibre-surface treatment on structural, thermal and mechanical properties of jute fibre and its composite. Bulletin of Materials Science, 32(1), 2009, 65-76. 